\title{
El concurso de la ciencia canónica en la realidad eclesial y en el saber jurídico universal*
}

\author{
The Study of Canon Law: Encompassing Ecclesial Reality \\ and Universal Legal Knowledge
}

RECIBIDO: 14 DE AGOSTO DE 2020 / ACEPTADO: 28 DE OCTUBRE DE 2020

\author{
Massimo DEL Pozzo \\ Profesor Ordinario de Derecho Canónico Constitucional \\ Pontificia Università della Santa Croce. Facoltà di Diritto Canonico. Roma \\ orcid 0000-0003-4816-1965 \\ delpozzo@pusc.it
}

Resumen: El artículo examina el concurso o convergencia de la ciencia canónica con la teología, el derecho civil y otras ciencias. El análisis identifica límites y restricciones en cada uno de los campos considerados. En lo que respecta al derecho canónico, existe una preocupante pérdida de identidad y cualificación del canonista (el desplazamiento de la justicia y racionalidad de los bienes de comunión a la regulación de la vida social) una falta de calidad y una escasa sensibilidad por la especialización y la sistemática. La ciencia teológica actual presenta una marcada fragmentación y falta de estructura orgánica, un destacado pragmatismo y una cierta subordinación mundana. Por otro lado, el pensamiento jurídico secular está dominado por el positivismo, el economicismo y el exceso de tecnologización. La situación es atribuible a un desconcierto metafísico, antropológico y espiritual más general, por lo que esperamos un "movimiento canonístico" que recupere el sentido realista de la juridicidad eclesial y ayude a iluminar también otras áreas del saber.

Palabras clave: Ciencia canónica, Teología, Derecho secular, Transdisciplinariedad, Realismo eclesiológico.
Abstract: The article examines the ways in which the study of canon law intersects with theology, civil law and other fields of knowledge. The analysis identifies the limits and limitations on each of the areas under discussion. With regard to canon law, there is a worrying loss of identity and adequate qualification among canon lawyers (in a shift from the justice and rationality of goods held in communion to the regulation of social life), a lack of quality standards and low sensitivity to the need for specialization and systematic approaches. Contemporary theological inquiry is fragmented and lacks an organic structure, and is markedly pragmatic and worldly in its concerns. At the same time, civil law thinking is driven by positivism and exaggerated senses of economicism and technologization. This situation may be due to a more general metaphysical, anthropological and spiritual confusion, which is why one aim here is to identify a "canonistical movement" capable of recovering a realistic sense of ecclesial legality and of shedding light on other areas of knowledge as well.

Keywords: Canonical Science, Theology, Secular Law, Transdisciplinarity, Ecclesiological Realism.

* Versione elettronica disponibile in italiano. 
SUMARIO: 1. Una situación compleja y problemática. 2. Las limitaciones de la canonística contemporánea. 2.1. La pérdida de identidad y cualificación. 2.2. Insuficiencias técnicas y especulativas. 2.3. La falta de un enfoque sistemático y especializado. 3. Las actuales restricciones de la teología. 4. La miopía de la sabiduría jurídica secular y de la cultura moderna. 5. Un movimiento jurídico "no juridicista".

\section{UNA SITUACIÓN COMPLEJA Y PROBLEMÁTICA}

as ideas que ofrece el ensayo del prof. Fantappiè encajan en una línea de investigación y reflexión en la que se manifiesta un pensamiento bien dotado de madurez y definición ${ }^{1}$. Al margen de una reconstrucción histórica perspicaz, que siempre se puede integrar y mejorar, surge el malestar y dolor del jurista eclesial ante lo poco que se aprecia y la escasa relevancia que se da en el panorama contemporáneo a la contribución de la canonística. Nos parece que este agravio también se siente y comparte en el entorno académico. Si bien se comprenden las reservas en cuanto al "paradigma codificador", el déficit actual parece ser más de concepto y contenido que de método o de medios; tiene que ver más con el "ser" que con el "hacer" derecho canónico. El divorcio, o mejor dicho la separación, entre derecho y teología, indica cuando menos una grieta epistemológica y una grave dificultad de comunicación y conocimiento. Asimismo, el aislamiento y marginación del ius canonicum en el saber jurídico universal y en general en la cultura contemporánea pone de manifiesto una importante límitación de diálogo y persuasión (haber suprimido las cátedras de derecho canónico en las universidades públicas es un triste testimonio de ello ${ }^{2}$ ). La cuestión de las reformas en la Iglesia (no nos parece que esta sea la verdadera emergencia eclesial) es solo la punta de un iceberg o el origen

1 Cfr. C. FANTAPPIÈ, Diritto canonico interdisciplinare. Spunti per un rinnovamento epistemologico; IDEM, Ecclesiologia e canonistica, Marcianum Press, Venezia 2015; IDEM, Per un cambio di paradigma. Diritto canonico, teologia e riforme nella Chiesa, EDB, Bologna 2019.

2 Cfr. G. FELICIANI, Il diritto canonico nelle università non ecclesiastiche, en GRUPPO ItAliano Docenti Di DiRitTo CANONICO (ed.), L'insegnamento del diritto canonico, Glossa, Milano 2014, 115-135; O. CondorelLI, La situación actual de la ciencia canónica, Ius Canonicum 49 (2009) 26-31. 
de un malestar más generalizado. El problema principal no es la crisis de rigor y disciplina en el pueblo de Dios (sin excluir en lo más mínimo a los pastores), sino el oscurecimiento de la justicia y de la prudencia en el orden de la caridad. La negación de la naturaleza jurídica de los bienes de comunión eclesial y civil empobrece gravemente las relaciones sociales y la consecución del bien común ${ }^{3}$.

El antijuridismo, o más bien la antijuridicidad, parece ser el resultado de una reacción nerviosa y desordenada a los excesos y deformaciones del pasado ${ }^{4}$. Aunque quizás se haya superado el pico de la crisis posconciliar, al menos en sus líneas maestras, (pensemos, por ejemplo, en los abusos litúrgicos, en el cuestionamiento del magisterio o en la ofuscación del derecho penal), no parece en todo caso que la resistencia de fondo se haya resuelto a nivel de mentalidad. La ajuridicidad (el prescindir del aspecto jurídico) es menos patente, pero no menos grave, que la antijuridicidad (prevención o acritud manifiesta). La frialdad y la indiferencia traicionan ciertamente con una trampa muy perniciosa: la consumación de un desapego definitivo. La recuperación del diálogo fructífero y de la sinergia operativa teológico-canónica no se puede reducir a buenas intenciones o meros deseos de reconciliación, sino a un profundo replanteamiento sustancial y epistemológico de ambos saberes.

La contribución de la ciencia canonística también parece ser deficiente en el contexto jurídico contemporáneo y en general en el debate cultural. El reconocimiento y consideración del ius canonicum a la hora de formar juristas, como hemos comentado, es muy marginal (se mantiene solo un interés predominantemente histórico o confesional) y, sobre todo, está "en vías de reducción”. Esta constatación produce cierta amargura, sobre todo si se compara con sus intercambios y contribución en el pasado, no solo remoto sino también reciente. Pretender un carácter específico y aspirar a una justicia "superior" y trascendente son un escaso consuelo aislacionista. El aislamiento intelectual y el retrai-

3 Cfr. P. Popović, "Bonum Commune Ecclesiae" and the Furidical Domain of the "Things" That Are Made Common in the Church, Ius Canonicum 59 (2019) 697-730.

4 Cfr. J. OTADUY, Giuridicità e prospettiva antigiuridica nell'interpretazione e ricezione del Vaticano II, en E. BAURA - M. DEL POZZO (eds.), Diritto e norma nella liturgia, Giuffrè, Milano 2016, 59-110. 
miento metodológico son signos claros de involución y clausura ${ }^{5}$. Más allá de los graves reduccionismos seculares (positivista, normativista y estatalista), en la base de esta separación científica presente hay un declive prospectivo: la transición de un «derecho espiritual para el mundo» a un «derecho de la Iglesia para la Iglesia» ${ }^{6}$. Esta articulación indica un enturbiamiento mental y una restricción proactiva para la juridicidad eclesial. La concepción de la justicia se vacía y se empobrece, al romper con la tradición grecorromano-escolástica ${ }^{7}$.

Habiendo esbozado un cuadro, quizás un tanto desconsolador, de la sinergia actual entre ciencia canónica, teológica, jurídico-general y otras disciplinas humanas, para intentar perfilar una pars construens ideal, superando el estéril "muro de las lamentaciones", nos limitamos a algunas sugerencias o provocaciones relacionadas con los tres principales ámbitos abordados. De hecho, el riesgo es el de emprender un diálogo de sordos. El punto de partida puede ser entonces un sincero examen de conciencia y una reflexión crítica sobre algunas causas de las posibles exclusiones.

\section{LAS LIMITACIONES DE LA CANONÍSTICA CONTEMPORÁNEA}

La sensación de soledad y exclusión nos invita a preguntarnos, en primer lugar, cuál es el motivo de la falta de consideración o de la prevención existente por parte de otras especialidades científicas (la necesidad de una mayor integración y colaboración probablemente no la sientan por igual los teólogos y los juristas seculares). La marginación a menudo corre el riesgo de convertirse en una autosegregación desdeñosa o un "espléndido aislamiento", si no se aceptan las advertencias y quejas explícitas o implícitas que se pueden inferir del contexto actual.

5 Ideas significativas, también por lo relevante de la ocasión, se incluyen en L. NAVARRO, Relazione conclusiva, en J. MiÑAMBRES (ed.), Diritto canonico e culture giuridiche nel centenario del Codex iurs canonici del 1917. Atti del XVI Congresso internazionale della Consociatio Internationalis Studio Iuris Canonici Promovendo, Roma 4-7 ottobre 2017, Edusc, Roma 2019, 933-935 (La formazione giuridica dei canonisti e la formazione canonistica dei giuristi).

6 La caracterización del pasaje en estos términos está formulada por O. Condorelli haciéndose eco de Stutz (A proposito di "Diritto canonico e culture giuridiche. Nel centenario del Codex Iuris Canonici del 1917”, presentación en la Universidad Pontificia de la Santa Cruz el 23 de enero de 2020, pendiente de publicación).

7 Cfr. M. VILLEY, La formation de la pensée juridique moderne, eds. S. Rials - É. Desmons, Puf, París 2013. 
La especie de eclipse jurídico en la Iglesia, a menudo denunciado, no puede limitar la perspectiva y la acción de los juristas eclesiales. Las limitaciones se nos presentan tanto en la forma como en la sustancia. En consecuencia, por decirlo de una manera quizá demasiado clara y lapidaria, no se puede ignorar una falta de identidad, calidad y sistematicidad ${ }^{8}$ en la canonística reciente.

\subsection{La pérdida de identidad y cualificación}

La primera y más sentida limitación de la canonística contemporánea parece ser la de su identidad y la competencia de especialización. La pregunta simple y banal sobre el objeto de la propia ciencia: "¿qué es el derecho?", a menudo deja perplejos a los juristas civiles ${ }^{9}$. La concepción normativista (el conjunto de las leyes...) no está del todo alejada de la forma mentis y del enfoque de los juristas eclesiales y con frecuencia está presente en las convicciones de los teólogos ${ }^{10}$. La concepción positivista en sentido lato es trivializante y extremadamente reduccionista para el arte del derecho. La involución legalista no es consecuencia directa de haber asumido el prototipo codicial, aunque en esta elección halla una clara correspondencia y un fuerte incentivo. Haber establecido y promovido el método exegético (incluso de modo autoritario) ha condicionado profundamente el modus operandi de los canonistas ${ }^{11}$. Así, el jurista, que es garante del justo orden social del pueblo de Dios, queda reducido, en la imaginación colectiva, al papel de un técnico del aparato legal

8 La necesidad de síntesis y claridad conduce claramente a irse a los extremos y a radicalizar los juicios.

9 Son aparentemente triviales en esta línea, pero nada evidentes: S. CoTTA, Perché il diritto, $2^{a}$ ed., La scuola, Brescia 1983; J. HervaDA, ¿Qué es el derecho? La moderna respuesta del realismo jurídico. Una introducción al derecho, Eunsa, Pamplona 2002 (trad. it.: Cos'è il diritto? La moderna risposta del realismo giuridico, Edusc, Roma 2013).

10 Para un análisis del derecho en la liturgia, cfr. p. ej. M. DEL POZzo, Dal diritto liturgico alla dimensione giuridica delle cose sacre: una proposta di metodo, di contenuto e di comunicazione interdisciplinare, Ius Ecclesiae 19 (2007) 589-608.

11 C. Fantappiè titula un párrafo de modo significativo: $\ll$ \$ 3 . El imperio del Código y el reino de la exégesis» (L'insegnamento del diritto canonico in Italia dal Concilio Vaticano II ai codici vigenti, en L'insegnamento del diritto canonico, cit., 40-45). M. GAS AIXENDRI propone iniciativas de superación en Nuevos desafíos del derecho canónico a cien años de la primera codificación (1917-2017), Tirant lo Blanch, Valencia 2018. 
o al de un intérprete de la norma. Evidentemente, un pensamiento jurídico "débil" e instrumental tiene poco que añadir al debate cognoscitivo. La dimensión de la justicia, en cambio, es intrínseca a la realidad social y, sobre todo, a los bienes mismos de la comunión (palabra, sacramentos y servicio de la caridad ${ }^{12}$ ). Despreciar el valor jurídico del fenómeno eclesial significa renunciar a un aspecto nada despreciable del patrimonio salvífico y a una sensibilidad cognitiva y operativa específica (el individualismo y el subjetivismo imperantes, por ejemplo, corrompen la objetividad y la solidaridad de la vida de fe). La fuerza del ius canonicum no radica tanto en el peso de la tradición o en la eficacia de la acción jerárquica como en el intrínseco deber y racionalidad de los bienes salvificos.

Para recuperar la identidad y el carácter específico de la canonística, el aspecto decisivo es reconocer el carácter intrínseco de la juridicidad eclesial. Por desgracia, la idea de una intervención externa y formal del factor jurídico está muy arraigada y extendida, especialmente entre quienes no están familiarizados con la práctica de la justicia. El perfil normativo y organizativo es secundario a la efectividad de los derechos: en la Iglesia existe el derecho no solo porque haya una comunidad y una socialidad estructurada, sino porque la fe, el culto y la solidaridad generan auténticas relaciones de justicia. El derecho aprovecha así un aspecto constitutivo, no absorbente ni dominante, aunque ciertamente relevante, del mysterium Ecclesiae. La presunción errónea de la funcionalidad o instrumentalidad del ius, que es la base de toda desviación pastoral, contrasta con el ineludible contenido humanista y veraz del fenómeno jurídico ${ }^{13}$. La relacionalidad y la prudencia propias de la justicia invalidan también la deriva idealista (formalismo, logicismo, etc.), muy extendida en el ámbito secular y no del todo ajena al mundo canonístico. En definitiva, solo la respuesta a la pregunta fundamental y la revitalización

12 «La naturaleza íntima de la Iglesia se expresa en una triple tarea: anuncio de la Palabra de Dios (kerygma-martyria), celebración de los Sacramentos (leiturgia) y servicio de la caridad (diakonia). Son tareas que se implican mutuamente y no pueden separarse una de otra» (BENEDICTO XVI, cart. enc. Deus caritas est, 25-XII-2005, n. 25.a).

13 El fundamento de todo derecho, incluso in Ecclesia, está en el estatuto ontológico de la persona humana. El ius no es un medio técnico ni un producto humano, sino una categoría de la realidad social. Los malentendidos que a menudo surgen sobre el ius divinum ponen de manifiesto las discrepancias sobre el concepto mismo de juridicidad. 
de la sabiduría clásica nos permiten dar coherencia y autoridad al trabajo del jurista eclesial y entablar un diálogo fructífero y constructivo.

\subsection{Insuficiencias técnicas y especulativas}

El discurso cualitativo es siempre espinoso e imponderable, corre el riesgo además de ser poco generoso con el compromiso de tantos investigadores y pensadores, aunque la actual escasez de "maestros" renombrados y reconocidos, sobre todo si se compara con el pasado, parece una señal poco alentadora para el florecimiento de la ciencia canónica. La calidad de la producción científica parece decisiva para la estima y el prestigio de una disciplina. Como es sabido, la enseñanza del derecho canónico, suprimida en las facultades de derecho italianas a finales del siglo XIX y principios del XX, se volvió a introducir gracias al valor y reconocimiento del trabajo de distinguidos exponentes del derecho canónico de la época ${ }^{14}$. Incluso la profundidad del así llamado "debate sobre el método" da fe de una vivacidad intelectual y un fermento de pensamiento notable y bastante amplio ${ }^{15}$. En la posmodernidad, las líneas de investigación se han vuelto más articuladas y complejas y los registros expositivos y comunicativos han cambiado. Cualquier pretensión de evaluación o comparación fácilmente corre el riesgo de simplificar y trivializar los términos de la comparación. En cualquier caso, el cambio de enfoque y expresión también puede ocultar un empobrecimiento sustancial de la especulación. La complacencia en la originalidad y carácter específico del modelo canónico no debe hacernos perder de vista el rigor del análisis y la seriedad de la lógica argumental. La mayor sectorización de las competencias, más que a una especialización y refinamiento del conocimiento, a menudo solo ha conducido a una fragmentación del saber y a una limitación del objeto y pensamiento de la perspectiva de la investigación. La visión global y la coherencia del desarrollo parecen indispensables en un enfoque orgánico y maduro del derecho eclesial.

14 Cfr. A. DE la Hera, Introducción a la ciencia del derecho canónico, Tecnos, Madrid 1980, 113-125; C. FANTAPPIÈ, Storia del diritto canonico e delle istituzioni della Chiesa, Il mulino, Bologna 2011, 274-275.

15 Cfr. M. NACCI, La cultura giuridica del Diritto canonico: il "laboratorio" degli anni trenta del Novecento in Italia, Apollinaris 85 (2012) 73-147. 
La impresión que se adquiere al leer muchos de los textos sobre derecho canónico, especialmente los de carácter didáctico y los manuales, es la de un persistente atraso con respecto a la profundidad y esmero de la correspondiente reflexión civil. En los últimos años, este déficit, que ya ha motivado quejas de algunos formadores o de quienes se dedican a la producción jurídica secular ${ }^{16}$, no solo no se ha cubierto, sino que incluso se ha acentuado más. No es casualidad que los compendios y tratados sean cada vez más escasos y aislados. La exigencia de una mayor atención a la justicia sustancial (sobre la que nos detendremos más adelante, infra $\$ 4$ ) no es suficiente para superar las deficiencias epistemológicas y metodológicas. El derecho es por definición una ciencia práctica y requiere habilidades técnicas y hermenéuticas adecuadas (como se dice a menudo: la forma también es sustancia). Sin perjuicio de una cierta generalización del problema, incluso en el contexto secular y evitando controversias ideológicas innecesarias, la conformación de algunas medidas recientes denota una redacción incierta y problemática ${ }^{17}$. La preparación o la contribución de los juristas eclesiales no siempre está a la altura de la tarea. Los aspectos procesales y la formalización de las actas (tan importantes de cara a una sensibilidad garantista) por ejemplo, se encuentran entre los perfiles más precarios y deficientes del sistema canónico vigente ${ }^{18}$.

16 Véase también infra notas 17 y 18 . El juicio de J. Hervada es bastante cáustico: «El estado actual de la ciencia canónica, en lo que respecta a la pureza metódica, es poco halagüeño y bien puede decirse que bastante deficiente». (Pensieri di un canonista nell'ora presente, Marcianum Press, Venezia 2007, 68, en términos más amplios 9-26, 65-81).

17 Cfr. p. ej. A. ZanotTi, A proposito di un diritto canonico periferico: ovvero il rischio della perifericità del diritto canonico, Stato, Chiese e pluralismo confessionale 2 (2017) 1-18, 23-I-2017; G. BonI, La recente riforma del processo di nullità matrimoniale. Problemi, criticità, dubbi (parte prima, seconda e terza), Stato, Chiese e pluralismo confessionale 9 (2016) 1-78, 7-III-2016; 10 (2016) 1-76, 14-III-2016; 11 (2016) 1-82, 21-III-2016; R.-M. RIVOIRE, Una lettura dell'istruzione Cor Orans sulla vita contemplativa femminile: sfide e prospettive, Stato, Chiese e pluralismo confessionale 24 (2019) 1-22.

18 Los problemas de la justicia administrativa y la penal son bien conocidos. Cfr. p. ej. S. Loppacher, Processo penale canonico e abuso sessuale su minori. Un'analisi dei recenti sviluppi normativi intorno al "delictum contra sextum cum minore" alla luce degli elementi essenziali di un giusto processo, Edusc, Roma 2017; G. PARISE, Ecclesia speculum iustitiae. Considerazioni intorno al giudizio amministrativo canonico presso il Supremo Tribunale della Segnatura Apostolica, Tabula fati, Chieti 2016; I. ZuANAZZI, Praesis ut prosis. La funzione amministrativa nella diakonía della Chiesa, Jovene, Napoli 2005. 
$\mathrm{Al}$ margen de las imponderables capacidades intelectuales, la excelencia está ligada principalmente a la selección y motivación de los agentes. Promover la formación canonistica es la vía de solución más fiable. Lamentablemente, la reducción de cátedras (en las universidades públicas), la multiplicación de tareas docentes (en las facultades eclesiásticas) y el descenso del número de estudiantes (tanto en unas como en otras) ciertamente no favorecen esta transición. La conciencia de una educación integral de los juristas, en lugar de una mera instrucción de simples operadores de los trribunales, garantizaría mejor en cualquier caso la identidad de los canonistas. Es bueno tener en cuenta que el jurista, sin minusvalorar su capacidad operativa, sigue siendo un humanista y un pensador integral.

\subsection{La falta de un enfoque sistemático y especializado}

Ya hemos mencionado la necesidad de adoptar siempre un enfoque jurídico amplio y global. La excesiva fragmentación o parcelación del saber, bastante extendida en muchos campos científicos modernos, es un serio obstáculo para captar la estructura fundamental y las conexiones de la realidad. A diferencia de sus colegas civilistas, los canonistas por lo general aún conservan un valor universalista e integral (la extensión y profundidad de la información legal y jurisprudencial no excluyen un buen dominio del conjunto). La prerrogativa, sin embargo, también constituye una límitación o una desventaja: la ausencia de una articulación especializada suficiente y madura. La producción científica a menudo procede más por repetición, superposición y reelaboración de conceptos que por una mejora y profundización orgánica y estructurada del tema. Los comunicadores y docentes "honestos" se limitan a proponer reajustes personales de los contenidos didácticos. Esta forma de proceder es comprensible y razonable, siempre que no oculte la consistencia y la experiencia del auténtico investigador o pensador ${ }^{19}$. Sin embargo, la necesidad de sintetizar o la naturaleza fungible de lo docente a menudo conduce a una parcialidad o a un carácter sumario de la formación y de su

19 El verdadero erudito se caracteriza, por un lado, por su personal contribución conceptual y autonomía de pensamiento y, por otro, por el afán de investigación y análisis crítico de las fuentes. 
transmisión. La originalidad del sistema que engloba al "científico" o, mejor aún, la virtud de dirigir y planificar del auténtico "maestro" ${ }^{20}$ son casi desconocidas o se dejan a la inspiración individual. Más allá de las divergencias epistemológicas y metodológicas relevantes, percibimos la falta de un sistema orgánico y de un plan de trabajo colectivo.

La relevancia está directamente relacionada con la cuestión cualitativa que acabamos de mencionar (supra $\$ 2.2$ ), pero también implica cierta contención por objeto o perspectiva cognitiva. La falta de una especulación especializada repercute en la profundidad y en el análisis. En las ciencias del espíritu, el conocimiento claramente procede no tanto de la experiencia y de la acumulación de información como de la reflexión y la demostración (la especulación y la argumentación juegan un papel decisivo). Sin perjuicio de la puesta en común o acuerdo en cuanto a las hipótesis, la colaboración y aportaciones de otros estudiosos no solo son motivadoras y cualificantes sino que también constituyen señales para proseguir y desarrollar la investigación ${ }^{21}$. La conocida imagen medieval de unos enanos a hombros de gigantes evoca no solo el valor de la tradición, sino también la necesidad de reconocer el valor de los demás ${ }^{22}$. La comparación entre especialistas es reducida en cuanto a número y exigua en contenido (las áreas de historia y matrimonial son una feliz excepción). Sin descuidar loables iniciativas personales o de grupo, la canonística se desenvuelve "con un orden disperso", por así decirlo, más en función de necesidades didácticas o contingentes que por inspiración investigadora y culminación temática. Hay una creciente necesidad de "crear redes" para alcanzar un paradigma común y compartido que me-

20 «Has tenido la gran suerte de encontrar maestros de verdad, amigos auténticos, que te han enseñado sin reservas todo cuanto has querido saber; no has necesitado de artimañas para "robarles" su ciencia, porque te han indicado el camino más fácil, aunque a ellos les haya costado duro trabajo y sufrimientos descubrirlo... Ahora, te toca a ti hacer otro tanto, con este, con aquel, ¡con todos!» (S. JosEMARÍa EsCRIVÁ, Surco, n. 733, en www. escrivaworks.org). Consideramos que el "científico" es aquel que logra elaborar, no teorías o investigaciones científicas particulares, sino un sistema de pensamiento orgánico y estructurado, y el "maestro" es el que viene a constituir una línea intergeneracional de estudio y profundización (el factor personal suele ser más excepcional y valioso que el conceptual, también porque normalmente lo presupone).

21 Cfr. también C. Cardona, Etica del lavoro educativo, Ares, Milano 1991.

22 Cfr. E. JEAnNEaU, Nani sulle spalle di giganti, Guida, Napoli 1969 (orig. franc.: Nani gigantium bumeris insidentes. Essai d'interprétation de Bernard de Chartres). 
jore la calidad de la investigación ${ }^{23}$. En cualquier caso, la especialización y la profundización sectorial presuponen siempre una visión de conjunto unitaria y coherente. En definitiva, el discurso esencial o fundamental (aunque no fundamentalista) orienta y resume el propósito, la forma y los contenidos de la elaboración canonística.

\section{LAS ACTUALES RESTRICCIONES DE LA TEOLOGÍA}

Las límitaciones e insuficiencias del método y contenido de la ciencia canónica actual no pueden ignorar las restricciones y, se podría decir, las "exclusiones" presentes en el campo teológico. En primer lugar, cabe señalar que la correspondencia interdisciplinar es desigual y no está equilibrada. Basta examinar las actas de los principales congresos canonísticos para darse cuenta de que las ponencias teológicas, en general preliminares o introductorias, distan mucho de ser escasas y aisladas ${ }^{24}$. Por el contrario, un examen inverso revela la ausencia casi total de contribución canonística, no solo en sectores menos permeables a la obligatoriedad intersubjetiva (dogmático, espiritual, escritural, etc. ${ }^{25}$ ) sino también en campos que también tienen un marcado valor social y disciplinar (litúrgico, sacramental, eclesiológico, moral, pastoral, etc.). Los canonistas sienten la necesidad de escuchar la voz de los teólogos, aunque luego a menudo se desvían de ella "refugiándose en el sistema normativo"; los teólogos, por su parte, manifiestan en general prejuicios o, quizás, desinterés por el enfoque jurídico ${ }^{26}$. La influencia del juridicismo y del autoritarismo postridentino sin duda ha impactado fuerte $y$ negativamente en la percepción del factor jurídico. La pretensión de

23 Cfr. también Francisco, const. ap. Veritatis gaudium, 27-XII-2017, n. 4.d; P. CARLOTTI, "Crear redes" entre instituciones, L'Osservatore Romano, 12-III-2020.

24 Pensemos en las reuniones anuales del Grupo Italiano de Profesores de Derecho Canónico (recogidas en Quaderni della Mendola, Glossa, Milano), los Congresos anuales de la Facultad de Derecho Canónico de la Universidad Pontificia de la Santa Cruz (recogidos en la serie de monografías jurídicas en Giuffrè, Milano), en las Jornadas canonísticas interdisciplinares organizadas por la Pontificia Universidad Lateranense (recogidas en los correspondientes volúmenes de la Lateran University Press, Ciudad del Vaticano), en los mismos congresos de de la Consociatio internationalis studio iuris canonici promovendo y otras iniciativas.

25 Sin embargo, hasta en estos ámbitos existe una dimensión de justicia.

26 Reiteramos que la indiferencia puede ser un mal aún mayor que la hostilidad abierta. 
autosuficiencia y preeminencia de la teología que, como veremos, es por otra parte muy relativa y parcial, en relación con la considerable influencia de las otras ciencias humanas, excluye o elimina de raíz la posible convergencia con la canonística. La sensación de opresión o asfixia deriva probablemente de la impresión de aridez, clausura y rigidez del enfoque jurídico ${ }^{27}$. Esta actitud, además de suponer una traición de grave amnesia histórica y doctrinal, disminuye la riqueza de los bienes eclesiales y los derechos del pueblo de $\operatorname{Dios}^{28}$.

Con referencia a las ideas y sugerencias ofrecidas por el prof. Fantappiè, conviene advertir sobre posibles malentendidos sobre el significado y el entorno de la operación cultural señalada. El deseo de «reconstrucción de una unidad fundamental del propio patrimonio dogmático, disciplinar, litúrgico» ${ }^{29}$ señalado, no quiere suponer una situación de precariedad e inestabilidad sobre el ser y el deber de ser de la Iglesia. El punto de partida de toda comparación y diálogo solo puede ser la claridad sobre la objetividad y trascendencia sobrenatural del fenómeno eclesial. No debemos repensar el objeto de estudio ni buscar nuevos elementos constitutivos sino respetar la naturaleza (también jurídica) de la Iglesia ${ }^{30}$. El mysterium Ecclesiae claramente (¡por definición!) se puede siempre comprender, configurar y exponer mejor ${ }^{31}$. La inexorable referencia realista no se refiere solo al enfoque jurídico, sino que de una manera aún más fecunda y significativa vincula la esencia de la estructura eclesial con los bienes de la comunión. Una especie de de profundis respecto al neotomismo no solo corre el riesgo de parecer un tanto drástica y poco generosa, sino que descuida el valor ontológi-

27 Cfr. C. Fantappiè, Per un cambio di paradigma, 122-123.

28 «Dar a conocer y aplicar las leyes de la Iglesia no es una traba para la presunta "eficacia" pastoral de quienes quieren resolver los problemas sin el derecho; al contrario, es la garantía de la búsqueda de soluciones no arbitrarias, sino verdaderamente justas y, por tanto, verdaderamente pastorales. Evitando soluciones arbitrarias, el derecho se convierte en un baluarte válido en defensa de los últimos y de los pobres, en un escudo protector para aquellos que corren el riesgo de ser víctimas de los poderosos de turno» (FranCISCO, Discurso a los participantes en la Plenaria del Pontificio Consejo para los Textos Legislativos, 21-II-2020).

29 Cfr. C. FANTAPPIÈ, Diritto canonico interdisciplinare..., $\$ 3$.

30 La llamada a la maduración de un nuevo paradigma desplaza la discusión de los contenidos a las formalidades científicas.

$31 \mathrm{Al}$ ser un misterio, nunca se puede agotar ni definir completamente. 
co y sustancial, así como histórico y didáctico, de la escolástica y de la metafísica clásica. Esta aclaración no quiere vincular inseparablemente el mensaje de salvación a un determinado sistema de pensamiento y expresión, quizás datado y circunscrito (aunque sea constantemente recomendado por el magisterio), sino que evita simplificaciones y liquidaciones historicistas ${ }^{32}$. La primera y más clara fuente de unidad epistemológica y sustancial reside precisamente en el sentire cum Ecclesia y en la referencia objetiva común al dato trascendente ${ }^{33}$. La convergencia hermenéutica debe reconocerse y perfeccionarse en el patrimonio ya existente. En esta línea, también puede redimensionarse el énfasis en las demandas de reforma y en el carácter sinodal ${ }^{34}$; no se trata de buscar o formular un nuevo modelo de comunión, sino de establecer y completar el diseño constitucional originario de la historia. Las reformas institucionales son solo un área de común interés y compromiso, no representan necesariamente el campo privilegiado del intercambio y entendimiento ${ }^{35}$. Más allá de las contingencias y aspiraciones ideológicas, el núcleo de una convergencia compuesta reside más bien en la estructura sacramental de la Iglesia.

Probablemente, la involución de las ciencias sagradas tampoco perdona a la teología. Más allá de la legítima y meritoria búsqueda de nuevas formas y modelos expresivos, el abandono, no tanto de los tratados clásicos (de estilos y registros consolidados), sino sobre todo de los temas más espinosos y consistentes de la dogmática, indica una evidente crisis de madurez. La pérdida de identidad y cualificación denunciada con respecto a la canonística probablemente concierne, a fortiori y, quizás más seriamente, a su "hermana mayor". El cambio de atención predominante del dogma a la moral, de la especulación a la práctica, denota el riesgo de un desajuste o extravío en el estatuto epistemológico fundamental de la teología y un declive en el tono y profundidad intelec-

32 Por ejemplo, la intención de san Juan Pablo II de aplicar algunas adquisiciones del pensamiento contemporáneo en la cultura cristiana tradicional, combinando la metafísica escolástica con la fenomenología existencialista, resultó ser muy fructífera y estimulante.

33 Cfr. también Benedicto XVI, Discurso a la Rota Romana, 21-I-2012.

34 Cfr. C. CARDIA, Il governo della Chiesa, Il mulino, Bologna 2002, 211-218 (La Chiesa come realtà sinodale e la collegialità come metodo di governo).

35 Vincular la juridicidad con la institucionalidad sería un reduccionismo indebido. 
tual ${ }^{36}$. La prevalencia de la experiencia sobre la razón, típica de la posmodernidad, condiciona el enfoque y las categorías cognitivas. En una época de cambio tan radical y profundo como la actual, no es de extrañar que casi todas las ciencias tengan que reubicarse y reorganizarse. La integración de la canonística en esta línea es un problema secundario y derivado, pero no demasiado despreciable ${ }^{37}$.

Hasta la falta de sistematicidad y organicidad une la evolución o el eclipse de ambas ciencias. Este enfoque, entre otras cosas, es más sincero y autorizado con respecto al saber teológico ${ }^{38}$. En la época contemporánea hemos asistido a una progresiva separación y distanciamiento entre las distintas ramas, también a nivel de supuestos y criterios de conceptualización ${ }^{39}$. El mundo teológico de hoy es muy variopinto e irregular. La "fragmentación" del saber teológico encuentra una clara justificación en la amplitud del tema y en el carácter analítico de los estudios, pero denota un desajuste de ideas y motivos y un grave prejuicio epistemológico ${ }^{40}$. La ruptura de la visión común y unitaria de la disciplina invalida su contribución y su integración, por así decirlo, interna. No es casualidad que la comparación con especialistas de otros saberes sea a veces más fácil y práctica que el intercambio con teólogos

36 El sentido de lo sagrado y de la adoración son los indicadores más seguros de la fidelidad al misterio cristiano (cfr. Jn 4,21-24).

37 La secuencia e integración entre liturgia, justicia y conducta pertenece a la promesa del pueblo elegido y se transmite al cristianismo: «En el ordenamiento de la alianza en el Sinaí (...) los tres aspectos del culto, el derecho y el ethos están indisolublemente entrelazados» (J. RATZINGER, Introduzione allo spirito della liturgia, San Paolo, Cinisello Balsamo 2001, 14).

38 El primero de los criterios para interpretar la Escritura conforme al Espíritu que la inspiró, delineado por el Concilio Vaticano II es: «Prestar mucha atención "al contenido y a la unidad de toda la Escritura"» (CCE 111-112).

39 Cfr. p. ej. G. LORIZIO - S. Muratore (eds.), La frammentazione del sapere teologico, San Paolo, Cinisello Balsamo 1998; R. Laurentin, La Chiesa oltre la crisi, San Paolo, Cinisello Balsamo 1992; P. PARENTE, La crisi della verità e il Concilio Vaticano II, Istituto padano di arti grafiche, Rovigo 1983; J. RATZINGER, Rapporto sulla fede. Colloquio con V. Messori, San Paolo, Torino 1985.

40 La superación del mero método escritural histórico-crítico es la intención que inspiró la trilogía de J. Ratzinger/Benedicto XVI: «La "exégesis canónica" -la lectura de los textos individuales de la Biblia en el marco de su integridad- es una dimensión que no está en contradicción con el método histórico-crítico, sino que lo desarrolla de manera orgánica y lo convierte en una verdadera y propia teología» (Gesù di Nazaret, Rizzoli, Milano 2007, Premessa, 15). 
de otras áreas. La referencia al conjunto garantiza la conspiratio ad unum y la compacidad y solidez de la construcción. La excesiva fragmentación o minuciosidad no solo vuelve estériles los estudios teológicos sino que corre el riesgo de desviarlos de su contexto primigenio. El debilitamiento de la doctrina determina a menudo la impresión de un cierto relativismo y una vaguedad perniciosa ${ }^{41}$.

La importancia pragmática de la teología también ha llevado a una acentuación inmanente, por así decirlo, de los saberes relacionados. De hecho, la influencia de muchas ciencias humanas parece estar creciendo en el debate y en la especulación teológica (pensemos en antropología, psicología, sociología, estética, etc.). La participación y discusión con eruditos y especialistas de otras ramas, a menudo dejando a un lado la misma consonancia de fe, tampoco es una práctica impropia e inusual. El peligro, no demasiado oculto, considerando también las voces y actitudes en los foros mediáticos, es el de una dependencia sociológica o una subordinación mundana al pensamiento dominante (un ascetismo débil o una espiritualidad etérea). Sin perjuicio de los problemas de comunicación y compenetración recíprocas, la interdisciplinariedad es una línea bastante extendida y practicada, aunque a menudo de manera formalista y superficial ${ }^{42}$. Propiamente, la evocación de la "transdiciplinariedad" quisiera ser una llamada a la síntesis y superación de barreras y divisiones entre especialidades bajo el carácter unitario de la realidad $^{43}$. Sin embargo, el papel impulsor y principal corresponde a la penetración de la verdad revelada. La falta de centralidad y referencia unívoca ocasiona un inexorable desajuste del conjunto. Como hemos mencionado, el apartamiento o segregación de la canonística como si se tratase de un gueto representa casi una excepción y una tendencia cultural dolorosa en el marco de la creciente inclinación teológica a sentir e incorporar otras ciencias. Probablemente, la claridad y perentoriedad de los supuestos de la argumentación jurídica se consideren un

41 Cfr. C. Fantappiè, Per un cambio di paradigma, 124.

42 Solo escucha la opinión de otros especialistas con curiosidad y cierto escepticismo.

43 «El principio vital e intelectual de la unidad del saber en la diversidad y en el respeto de sus expresiones múltiples, conexas y convergentes es lo que califica la propuesta académica, formativa y de investigación del sistema de los estudios eclesiásticos, ya sea en cuanto al contenido como en el método» (FranCISCO, const. ap. Veritatis gaudium, n. 4.c). 
freno u obstáculo al contraste y a la discusión ${ }^{44}$. La orientación práctica de la teología actual también acentúa rivalidades y posibles contrastes metodológicos.

\section{LA MIOPÍA DE LA SABIDURÍA JURÍDICA SECULAR Y DE LA CULTURA MODERNA}

Como es bien sabido, la ciencia canónica y la civil han estado en estrecho contacto durante mucho tiempo. Basta pensar en la relación entre canonistas y legistas en la época del ius commune. Contribuciones y estímulos han sido intensos, constantes y recíprocos durante varios siglos $^{45}$. Sin embargo, no hay duda de que la elaboración del ius canonicum ha proporcionado el fundamento de muchas instituciones y categorías del derecho secular. La divergencia actual, que ignora las raíces y fundamentos culturales del derecho estatal (al menos el occidental), representa cuando menos una forma grave de miopía o de presbicia (aunque el problema no es solo histórico y cultural). No obstante, las causas de este desapego no son unilateralmente atribuibles a la emancipación de los ordenamientos estatales y a la secularización de la sociedad. Analizar en profundidad las razones de la separación va más allá de las posibilidades y capacidad de estas páginas, sin embargo, no nos cabe duda de que el declive endógeno de la canonística, la clausura apologética (pensemos en particular en el Ius publicum ecclesiasticum), la autocomplacencia y el aislamiento metodológico han contribuido a reducir los contactos. Las cuestiones mixtas y el derecho concordatario o las escasas referencias comparativas representan un exiguo ámbito de encuentro (y con frecuencia de conflicto) entre dos sistemas de pensa-

44 La mentalidad jurídicista implica la suposición o pretensión de decir la última palabra. En cambio, una visión abierta y reflexiva de la justicia evita "sacralizar" el texto legal. En esta línea, la referencia constante al ius condendum y la perfectibilidad del derecho formalizado ofrecen un espacio más sereno y equilibrado para el diálogo y la discusión.

45 Cfr. p. ej. F. Calasso, Introduzione al diritto comune, Giuffrè, Milano 1970; M. BELloMO, L'Europa del diritto comune, Il Cigno Galileo Galilei, Roma 1994; P. GROSSI, L'ordine giuridico medievale, Laterza, Roma-Bari 1997; IDEM, L'Europa del diritto, Laterza, Roma-Bari 2010; M. CARAVALE, Ordinamenti giuridici dell'Europa medievale, Il mulino, Bologna 1994. 
miento ahora muy distantes. La legislación canónica a menudo tira o se arrastra a remolque de las demandas y presiones seculares ${ }^{46}$. Para evitar actitudes estériles de suficiencia y arrogancia, es útil señalar que la originaria prioridad y prevalencia canonística ha sido claramente suplantada por el derecho civil. El desarrollo y progreso de la ciencia jurídica secular en la época moderna y contemporánea, al menos a nivel técnico-instrumental y operativo, no halla una correspondencia adecuada en el contexto canónico. La total inversión de tendencia cuantitativa y técnico-cualitativa deja claro que la falta de un diálogo "constructivo" daña no poco a la ciencia canónica. De manera más general, la comunicación e implementación de las adquisiciones de otros saberes y la apertura al fenómeno religioso, como estructurado y disciplinado en la Iglesia, es cada vez más indispensable ante la fluidez y complejidad de la situación actual.

Intentando evitar reconstrucciones histórico-especulativas sumarias y parciales, es necesario reiterar que la actual falta de comunicación deriva no tanto de la falta de interés o de contenidos comunes como de la profunda divergencia conceptual. La afirmación del principio de inmanencia, del individualismo y del liberalismo, ha producido una ruptura o corte irremediable con el pasado y con la tradición jurídica. El punto de inflexión de la época es el paso de la racionalidad y objetividad de lo justo al voluntarismo y al consensualismo legislativo ${ }^{47}$. La atención, en cierto sentido, ha pasado del objeto y el bien al sujeto y a los valores. El proceso se ha desarrollado claramente con el tiempo; el normativismo imperante en la esfera secular no es más que el producto relativamente lineal del voluntarismo, del individualismo, del racionalismo, del idealismo y del positivismo, solo por mencionar algunas fases o etapas filosóficas significativas ${ }^{48}$. Las categorías de derecho subjetivo, de reivindi-

46 Esta importancia es particularmente evidente en las recientes intervenciones legislativas en materia penal, de comunicación, económica y financiera.

47 Guillermo de Occam y Francisco Suárez fueron determinantes de cara a cambios muy significativos en la cultura europea en esta línea, cfr. M. VILLEY, La formation de la pensée juridique moderne, cit.

48 Cfr. en general J. Hervada, Historia de la ciencia del derecho natural, Eunsa, Pamplona 1987. También ofrece ideas interesantes para repensar R. Di MARCO, L'intelligenza del diritto. Sulla "oggettività" come problema giuridico ... oltre il positivismo, Edizioni scientifiche italiane, Napoli 2019. 
cación, de interés legítimo, perfilan claramente la acentuación del valor subjetivo del ius. El derecho moderno está concebido sobre todo como un instrumento operativo (estado de derecho) y moderador (estatus social) del poder. Evidentemente, la canonística no ha sido insensible a las transformaciones y evoluciones del derecho secular (sufriéndolas más que orientándolas). Sin embargo, es bueno tener en cuenta que, si bien en el pasado existía una estrecha afinidad y puntos de vista comunes con los juristas civiles, hoy existe un abismo y una brecha notable (aunque no irremediable) en términos de principios y forma de proceder. Por tanto, el normativismo ha marcado una ruptura con respecto al realismo y a la prudencia del ius. El discurso identitario esbozado (supra $\$ 2.1$ ) resulta entonces fundamental y perjudicial para definir los términos y el sentido de la comparación.

La contribución más valiosa de la canonística a la comunidad científica está ligada, a nuestro juicio, a la continuidad y desarrollo del enfoque clásico del saber (ars boni et aequi) y de la atención al caso individual. La posible contribución, sin embargo, no es "de sentido único", sino recíproca. Como se ha dicho, la preservación de la justicia y la tradición del sistema canónico se corresponde con la mayor innovación y elaboración del derecho civil actual. La apertura a los cambios sociales y a las reivindicaciones civiles y racionales ha producido la maduración de la participación y mayores garantías (pensemos en la participación en el proceso administrativo, el acceso a las actas, la transparencia y el control). Desde un punto de vista instrumental y metodológico, la ciencia jurídica secular parece mucho más sofisticada y avanzada que la ciencia eclesial. La adaptación a los estándares civiles generalizados ya ha llevado a la aplicación, quizás un poco forzada y apresurada, de medidas regulatorias en los ámbitos de la comunicación, económicos, financieros, penales, etc. Entre otras cosas, la colaboración esperada no solo se refiere al refinamiento de los llamados bienes, por así decir, instrumentales (patrimoniales, procesales, administrativos, etc.) sino también a la dinámica en el ejercicio del gobierno eclesiástico ${ }^{49}$.

49 Cfr. M. DEL Pozzo, La struttura costituzionale del governo ecclesiastico, Edusc, Roma 2020, 63-70 y 113-124. 


\section{UN MOVIMIENTO JURÍDICO "NO JURIDICISTA"}

El análisis realizado ha esbozado cómo la crisis de sinergia científica del derecho canónico con la teología, el derecho civil y los demás saberes es algo espinoso e irregular; sin embargo, no concierne exclusivamente al empañamiento y repliegue canonístico, involucra a todas las ciencias sagradas y en general a la cultura posmoderna. La desorientación y el desconcierto antropológico, moral y espiritual en curso nos parece, a decir verdad, mucho más grave que el actual eclipse eclesiológico y teológico ${ }^{50}$. En este marco, quizás no demasiado alentador, aunque no falten motivos de luz y optimismo, se redimensiona y circunscribe la cuestión canonística.

Sin embargo, la exclusión del debate intelectual y el enturbiamiento de la dimensión de la justicia son preocupantes, especialmente en la realidad eclesial. Reiteramos que sin una profunda reflexión crítica y un sincero examen de conciencia es imposible alcanzar una recomposición armónica. La experiencia del matrimonio enseña cuánto sufrimiento e incomodidad genera la separación conyugal, especialmente a los niños (verdaderas víctimas inocentes del conflicto). La imagen puede servir para entender que el desapego y alejamiento -sin que se pueda hablar de un divorcio deliberado- entre derecho canónico y teología perjudica al bien de la Iglesia, pero sobre todo al testimonio ante el mundo. La concepción del derecho y en general de la sociedad civil sufren quizás las consecuencias más graves y profundas. Hemos subrayado, quizás excediéndonos, las limitaciones de la canonística actual (más claras y conocidas para nosotros), pero nos parece que las insuficiencias reveladas por la especulación teológica y civilista son probablemente aún más radicales y sustanciales. Es necesario redescubrir y potenciar el patrimonio común y adquirido, repensar el propio estatuto epistemológico a partir de la identidad y pertenencia específicas. La crisis denunciada denota in primis una formación y cualificación científica equívocas. En este contexto, la referencia a la "transdiciplinariedad" resulta profética y estimulante: la convergencia transdisciplinar busca una forma de síntesis y superación

50 La preocupante situación de crisis antropológica y teológica la describió R. SARAH con tonos particularmente dramáticos, en Si fa sera e il giorno ormai volge al declino, Intervista con N. Diat, Cantagalli, Siena 2019. 
en la trascendencia intrínseca del objeto ${ }^{51}$. La fecundidad de la interacción deriva de la fidelidad a la dimensión y ratio cognitiva (que cada uno haga bien su trabajo), sin extrapolaciones ni interferencias indebidas. La pretensión de preeminencia o autosuficiencia daña la alteridad de la perspectiva (pensemos en los perjuicios del juridicismo o panteologismo). En esta línea, la realidad plural y misteriosa de la Iglesia se impone asimismo sobre los diversos perfiles de observación y sobre la propia contingencia de las categorías de estudio. La indicación magisterial puede claramente iluminar en especial a las ciencias sagradas; de todos modos, la recuperación de la posición y la cualificación del ius canonicum también puede recuperar una función demostrativa frente al mundo ${ }^{52}$.

Todos los procesos llevan tiempo, los culturales con mayor razón y los eclesiales de una manera aún más paciente y laboriosa. El diálogo presupone claramente voluntad de intercambio y ciertamente no puede ser impuesto ni forzado. Más que "diálogo", que es solo un esquema formal (del que muchas veces se ha abusado por no ser concluyente), es necesario desarrollar una "comprensión” más orgánica y completa del mysterium Ecclesiae, del bien jurídico o del estatuto ontológico de la persona ${ }^{53}$. La supuesta operación no es de fachada ni de medios, sino de contenido y resultado. Las obvias dificultades de comprensión exigen in primis escuchar las razones y quejas de los demás, incluso la percepción

51 «n este sentido, es sin duda positivo y prometedor el redescubrimiento actual del principio de la interdisciplinariedad: No solo en su forma "débil", de simple multidisciplinariedad, como planteamiento que favorece una mejor comprensión de un objeto de estudio, contemplándolo desde varios puntos de vista; sino también en su forma "fuerte", de transdisciplinariedad, como ubicación y maduración de todo el saber en el espacio de Luz y de Vida ofrecido por la Sabiduría que brota de la Revelación de Dios» (Francisco, Veritatis gaudium, n. 4.c). La actitud sapiencial resume la estructuración pluriforme de los bienes de comunión.

$52 \ll$ Pero el deber de la Iglesia y su mérito histórico de proclamar y defender en todo lugar y en todo tiempo los derechos fundamentales del hombre, no la eximen, antes la obligan a ser ante el mundo "speculum iustitiae, espejo de iusticia". La Iglesia tiene al respecto una responsabilidad propia y específica» (S. JUAN PABLO II, Discurso a la Rota Romana, 17-I-1979).

53 Los tres ámbitos señalados corresponden al núcleo de la eclesiología, de la juridicidad en general y de las ciencias humanas. En esta última dirección es interesante notar que el fenómeno jurídico es siempre inherente a la socialidad humana, en este sentido se ha relacionado con una suerte de trascendental del ser humano (cfr. G. Lo CASTRO, Il mistero del diritto. I - Del diritto e della sua conoscenza, Giappichelli, Torino 1997, 1-2). 
desigual del problema es un hecho importante. La resistencia o prevención del frente teológico y civil se puede superar reconociendo humildemente las limitaciones históricas y coyunturales y demostrando un efectivo cambio de perspectiva y mentalidad.

La vía de la recomposición se inicia demoliendo el "muro de separación" que actualmente divide a canonistas de teólogos y otros juristas. Una adecuada presentación del "buen" derecho (estrictamente hablando, todo calificativo es redundante) y la continuidad de la experiencia jurídica pueden ayudar a superar prejuicios y desconfianzas que se hayan arraigado ${ }^{54}$. Una señal tangible y decisiva de conversión metodológica es pasar de una "forma legal" cerrada y divisoria a una "relación jurídica" abierta y unificada ${ }^{55}$. Una atención aún mayor al ius condendum o a las reivindicaciones garantistas y procesales es un incentivo fructífero a la convergencia. La necesidad de recuperar el objeto y misión del jurista puede superar la oposición de escuelas y orientaciones. En esta dirección solo podemos esperar un "movimiento canonístico" alternativo al débil pensamiento secular y a los reduccionismos teológicos y culturales, sin complejos antievangélicos y sin aspiraciones revanchistas. Claramente no se trata de una vuelta al juridicismo postridentino, sino de promover la dimensión de justicia del patrimonio salvífico ${ }^{56}$. La identidad y la armonía proactiva constituyen tan solo la base de este largo viaje.

54 Es la experiencia adquirida y renovada personalmente en la enseñanza de Perfiles jurídicos de la liturgia de la Iglesia, curso desarrollado por la Facultad de Teología de la Universidad Pontificia de la Santa Cruz; para el enfoque y su entorno cfr. M. DEL Pozzo, La giustizia nel culto. Profili giuridici della liturgia della Chiesa, Edusc, Roma 2013.

$55 \ll$ La juridicidad no revela una sustancia, sino una relación. Siempre que decimos que algo es jurídico estamos nombrando una relación» (J. HERVADA, Introduzione critica al diritto naturale, Giuffrè, Milano 1990, 34).

56 No es casualidad que la insistente llamada a la caridad y a la misericordia (que van más allá de la perspectiva de la justicia) haya llevado a la Iglesia y al Pontífice a pensar principalmente, al menos dentro de la estructura jerárquica, en la verdad y en la justicia. cfr. p. ej. Francisco, Carta al pueblo de Dios, 20-VIII-2018. 


\section{Bibliografía}

Bellomo, M., L'Europa del diritto comune, Il Cigno Galileo Galilei, Roma 1994.

BONI, G., La recente riforma del processo di nullità matrimoniale. Problemi, criticità, dubbi (parte prima, seconda e terza), Stato, Chiese e pluralismo confessionale 9 (2016) 1-78, 7-III-2016; 10 (2016) 1-76, 14-III2016; 11 (2016) 1-82, 21-III-2016.

Calasso, F., Introduzione al diritto comune, Giuffrè, Milano 1970.

Caravale, M., Ordinamenti giuridici dell'Europa medievale, Il mulino, Bologna 1994.

CARDIA, C., Il governo della Chiesa, Il mulino, Bologna 2002, 211-218 (La Chiesa come realtà sinodale e la collegialità come metodo di governo).

Cardona, C., Etica del lavoro educativo, Ares, Milano 1991.

CARLOTTI, P., "Fare rete" tra istituzioni, L'Osservatore Romano, 12-III2020.

Condorelli, O., La situación actual de la ciencia canónica, Ius Canonicum 49 (2009) 13-35.

CotTa, S., Perché il diritto, La scuola, Brescia 1983.

DE LA HeRA, A., Introducción a la ciencia del derecho canónico, Tecnos, Madrid 1980, 113-125.

Del Pozzo, M., Dal diritto liturgico alla dimensione giuridica delle cose sacre: una proposta di metodo, di contenuto e di comunicazione interdisciplinare, Ius Ecclesiae 19 (2007) 589-608.

- La struttura costituzionale del governo ecclesiastico, Edusc, Roma 2020, 63-70, 113-124.

—, La giustizia nel culto. Profili giuridici della liturgia della Chiesa, Edusc, Roma 2013.

Di MARCO, R., L'intelligenza del diritto. Sulla "oggettività" come problema giuridico ... oltre il positivismo, Edizioni scientifiche italiane, Napoli 2019.

Fantappiè, C., Ecclesiologia e canonistica, Marcianum Press, Venezia 2015.

- Per un cambio di paradigma. Diritto canonico, teologia e riforme nella Chiesa, EDB, Bologna 2019. 
-, Storia del diritto canonico e delle istituzioni della Chiesa, Il mulino, Bologna 2011, 274-275.

FELICIANI, G., Il diritto canonico nelle università non ecclesiastiche, en Gruppo Italiano Docenti di Diritto Canonico (ed.), L'insegnamento del diritto canonico, Glossa, Milano 2014, 115-135.

FRANCESCO, cost. ap. Veritatis gaudium, 27-XII-2017.

—, Discorso ai partecipanti alla Plenaria del Pontificio Consiglio per i Testi Legislativi, 21-II-2020.

—, Lettera al popolo di Dio, 20-VIII-2018.

Gas Aixendri, M., Nuevos desafíos del derecho canónico a cien años de la primera codificación (1917-2017), Tirant lo Blanch, Valencia 2018.

Giovanni PaOlo II, Discorso alla Rota Romana, 17-I-1979.

Grossi, P., L'ordine giuridico medievale, Laterza, Roma-Bari 1997.

—, L'Europa del diritto, Laterza, Roma-Bari 2010.

HeRvaDA, J., ¿Qué es el derecho? La moderna respuesta del realismo jurídico. Una introducción al derecho, Eunsa, Pamplona 2002 (trad. it.: Cos'è il diritto? La moderna risposta del realismo giuridico, Edusc, Roma 2013).

—, Historia de la ciencia del derecho natural, Eunsa, Pamplona 1987.

—, Introduzione critica al diritto naturale, Giuffrè, Milano 1990.

Jeanneau, E., Nani sulle spalle di giganti, Guida, Napoli 1969 (orig. franc.: Nani gigantium bumeris insidentes. Essai d'interprétation de Bernard de Chartres).

Laurentin, R., La Chiesa oltre la crisi, San Paolo, Cinisello Balsamo 1992.

Lo Castro, G., Il mistero del diritto. I - Del diritto e della sua conoscenza, Giappichelli, Torino 1997.

LOPPACHER, S., Processo penale canonico e abuso sessuale su minori. Un'analisi dei recenti sviluppi normativi intorno al "delictum contra sextum cum minore" alla luce degli elementi essenziali di un giusto processo, Edusc, Roma 2017.

Lorizio, G. - Muratore, S. (eds.), La frammentazione del sapere teologico, San Paolo, Cinisello Balsamo 1998.

NACCI, M., La cultura giuridica del Diritto canonico: il "laboratorio" degli anni trenta del Novecento in Italia, Apollinaris 85 (2012) 73-147. 
Navarro, L., Relazione conclusiva, in Diritto canonico e culture giuridiche nel centenario del Codex iuris canonici del 1917. Atti del XVI Congresso internazionale della Consociatio Internationalis Studio Iuris Canonici Promovendo, Roma 4-7 ottobre 2017, a cura di J. Miñambres, Edusc, Roma 2019, 927-938.

OTADUY, J., Giuridicità e prospettiva antigiuridica nell'interpretazione e ricezione del Vaticano II, en E. BAURA - M. DEL Pozzo (eds.), Diritto e norma nella liturgia, Giuffrè, Milano 2016, 59-110.

Parente, P., La crisi della verità e il Concilio Vaticano II, Istituto padano di arti grafiche, Rovigo 1983.

PARISE, G., Ecclesia speculum iustitiae. Considerazioni intorno al giudizio amministrativo canonico presso il Supremo Tribunale della Segnatura Apostolica, Tabula fati, Chieti 2016.

Popović, P., "Bonum Commune Ecclesiae" and the Furidical Domain of the "Things" That Are Made Common in the Church, Ius Canonicum 59 (2019) 697-730.

RATZINGER, J., Introduzione allo spirito della liturgia, San Paolo, Cinisello Balsamo 2001, 14.

—, Rapporto sulla fede. Colloquio con V. Messori, San Paolo, Torino 1985.

RIVOIRE, R.-M., Una lettura dell'istruzione Cor Orans sulla vita contemplativa femminile: sfide e prospettive, Stato, Chiese e pluralismo confessionale 24 (2019) 1-22.

SARAH, R., Si fa sera e il giorno ormai volge al declino, Intervista con N. Diat, Cantagalli, Siena 2019.

VILLEY, M., La formation de la pensée juridique moderne, eds. S. Rials É. Desmons, Puf, Paris 2013.

ZanotTi, A., A proposito di un diritto canonico periferico: ovvero il rischio della perifericità del diritto canonico, Stato, Chiese e pluralismo confessionale 2 (2017) 1-18, 23-I-2017.

ZuAnaZZI, I., Praesis ut prosis. La funzione amministrativa nella diakonía della Chiesa, Jovene, Napoli 2005. 